\title{
Drilling machinability of resin-less "green" composites reinforced by bamboo fiber
}

\author{
A. Mizobuchi, H. Takagi, T. Sato \& J. Hino \\ Institute of Technology and Science, The University of Tokushima, Japan
}

\begin{abstract}
This paper deals with the machinability of resin-less bamboo composites ("green" composites) in drilling. The machinability is estimated by thrust force, specific cutting force, hole appearance, chip form and tool wear when drilling "green" composites, bamboo and Japanese cedar using a metal drill and a wood drill. Experimental conditions are a cutting speed of $5 \mathrm{~m} / \mathrm{min}$ to $25 \mathrm{~m} / \mathrm{min}$ and a feed rate of $0.006 \mathrm{~mm} / \mathrm{rev}$ to $0.06 \mathrm{~mm} / \mathrm{rev}$. The thrust force of "green" composites is larger than that of other workpieces such as Japanese cedar and bamboo. The specific cutting force of "green" composites with high tensile strength is large. In the case of the metal drill, the chip length of "green" composites is very long compared to that of other workpieces. Various disfigurements formed around the hole in the drilling of "green" composites are small at a cutting speed of $15 \mathrm{~m} / \mathrm{min}$ and a feed rate of $0.03 \mathrm{~mm} / \mathrm{rev}$. On the other hand, the wood drill is inadequate to drill "green" composites. To decrease the disfigurements around the drilled hole, it is considered that a single bamboo fiber of the composites should be cut by a sharp cutting edge that is equipped with an electroplated diamond tool.
\end{abstract}

Keywords: resin-less bamboo composites, machinability, drilling.

\section{Introduction}

Biodegradable composite materials, which are made from natural fibers and a biodegradable resin, have recently appeared as an alternative to polymer materials made of petroleum. For example, the biodegradable polymers are used for an interior trim panel of car and a chassis of cellular phone. These several products are made by forming the materials poured into a mold as well as the conventional polymer molding. In order to increase the applicabilities of 


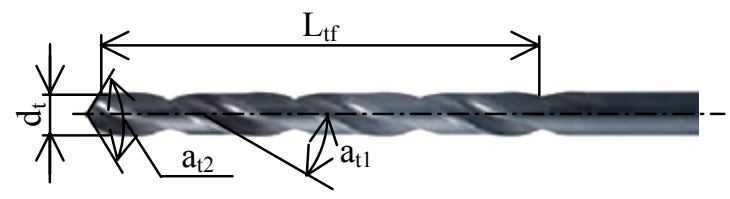

(a) Metal drill

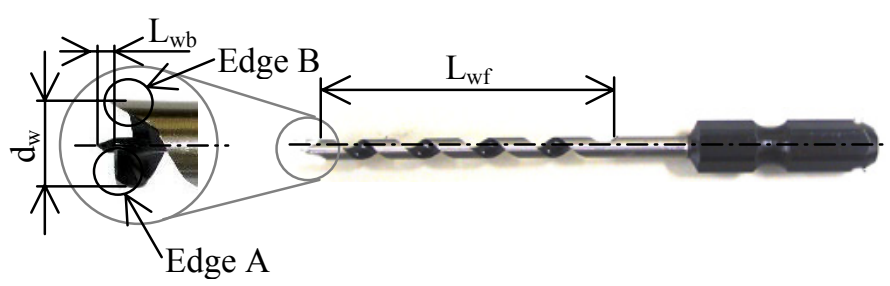

(b) Wood drill

Figure 1: $\quad$ Photograph of drills.

biodegradable polymers, machining such as milling, cutting and drilling is necessary, and is able to produce various products with more complex shapes. Compared with the molding, moreover, the machining requires no molds, and enables limited production of diversified products. However, many researchers have been studying the mechanical properties of the biodegradable composites [1-8], but there are few studies about the machining. This paper took up drilling as an example of the machining in order to investigate the machinability of resin-less "green" composites which were examined by thrust force, chip form, hole appearance and tool wear.

\section{Experimental methods and conditions}

The workpieces used are resin-less "green" composites (GC), Japanese cedar (CE) and bamboo (BA), and their dimension is 100 (length) $\mathrm{x} 15$ (width) $\mathrm{x}$ $2 \mathrm{~mm}$ (thickness). The resin-less "green" composites were fabricated by a hot-pressing method under a forming temperature of $393 \mathrm{~K}$, and a forming pressure of $10 \mathrm{MPa}(\mathrm{GC} 10)$ and $50 \mathrm{MPa}(\mathrm{GC} 50)$ was used. The tensile strength of the fiber direction of $\mathrm{GC}, \mathrm{CE}$ and $\mathrm{BA}$ was about 320,100 and $170 \mathrm{MPa}$, respectively. The process of manufacture and the mechanical properties of GC used in the experiments have been described [9].

Drills are commonly used in metalworking and woodworking. The drills used in the experiments are a metal drill for metalworking and a wood drill for woodworking, as shown in Fig. 1. The tool geometries of the metal drill are a tool material of high speed tool steels (JIS SKH51), a drill diameter of $\mathrm{d}_{\mathrm{t}}=2 \mathrm{~mm}$, a flute length of $\mathrm{L}_{\mathrm{tf}}=29 \mathrm{~mm}$, a helix angle of $\mathrm{a}_{\mathrm{t} 1}=30 \mathrm{deg}$ and a point angle of $\mathrm{a}_{\mathrm{t} 2}=118$ deg. The wood drill has an edge combined with a short auger bit with a brad point. The tool geometries of the wood drill are a tool material of carbon steel (JIS S55C), a brad point length of $\mathrm{L}_{\mathrm{wb}}=2 \mathrm{~mm}$, a drill diameter of $\mathrm{d}_{\mathrm{w}}=3 \mathrm{~mm}$ 


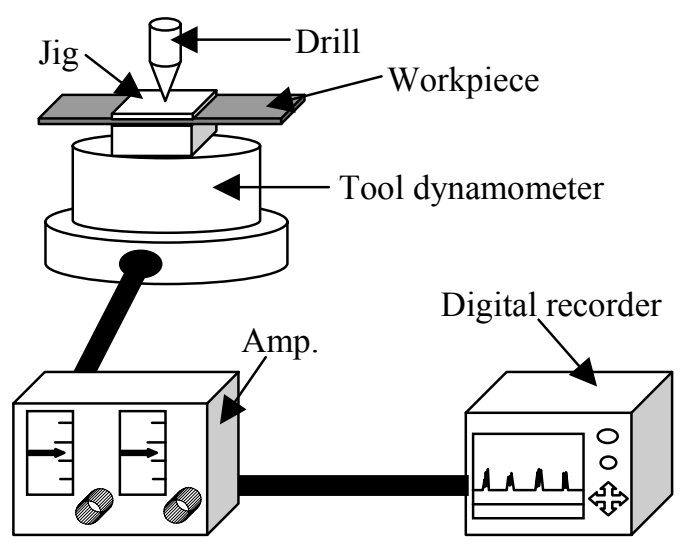

Figure 2: Schematic drawing of the drilling system.

and a flute length of $\mathrm{L}_{\mathrm{wf}}=45 \mathrm{~mm}$. In the case of the wood drill, the brad point drills the hole before the auger bit arrives on the workpiece. Experimental conditions are a cutting speed of $5 \mathrm{~m} / \mathrm{min}$ to $25 \mathrm{~m} / \mathrm{min}$ and a feed rate of 0.006 $\mathrm{mm} / \mathrm{rev}$ to $0.06 \mathrm{~mm} / \mathrm{rev}$.

Figure 2 illustrates the schematic drawing of the drilling system. The machine tool used in the experiments is a NC milling machine (KE55, Makino milling machine Co., Ltd.) with a Fanuc system. The workpiece is fixed by a jig mounted on a tool dynamometer (AST-BH, Sato Co., Ltd). Backing plates to prevent the occurrence of various disfigurements such as burr and fuzz aren't used on the entrance and exit of the workpiece. During drilling, the thrust force measured by the tool dynamometer is recorded on a digital recorder (NR-2000, Keyence Co., Ltd.). The drilled hole, the chip form and the tool wear are observed by a digital microscope (VH-7000, Keyence Co., Ltd.).

\section{Experimental results}

\subsection{Thrust force}

Figure 3 shows the thrust force curves when drilling workpieces using the metal drill at the cutting speed of $15 \mathrm{~m} / \mathrm{min}$ and the feed rate of $0.03 \mathrm{~mm} / \mathrm{rev}$. The thrust force of GC increases immediately when drilling processes are started. The variety of thrust force is approximately constant during drilling. The thrust force becomes zero as soon as the tool end arrives at the back surface of the workpiece. The thrust force of GC10 is slightly smaller than that of GC50. The thrust force of BA is very small, and the progressive curve is similar with a variation pattern of GC. However, the thrust force of $\mathrm{CE}$ shows intensive alteration when drilling a hard layer such as woodgraining.

Figure 4 shows the thrust force curve in the drilling of workpieces using the wood drill. The experimental conditions are as same as in Fig. 3. The variation of thrust force is the impetuous in drilling of GC. The thrust force increases 


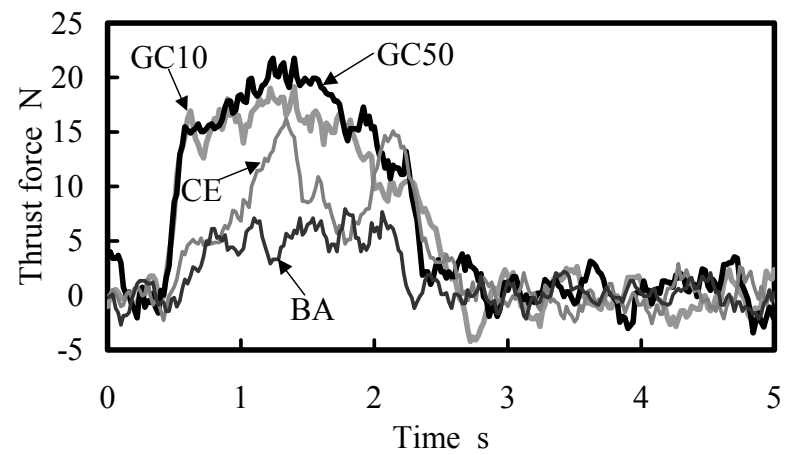

Figure 3: Variation of thrust force when drilling workpieces using the metal drill.

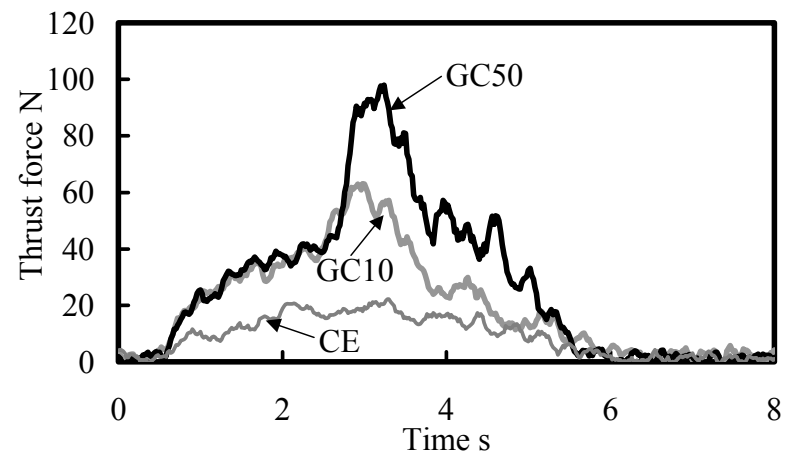

Figure 4: Variation of thrust force when drilling workpieces using the wood drill.

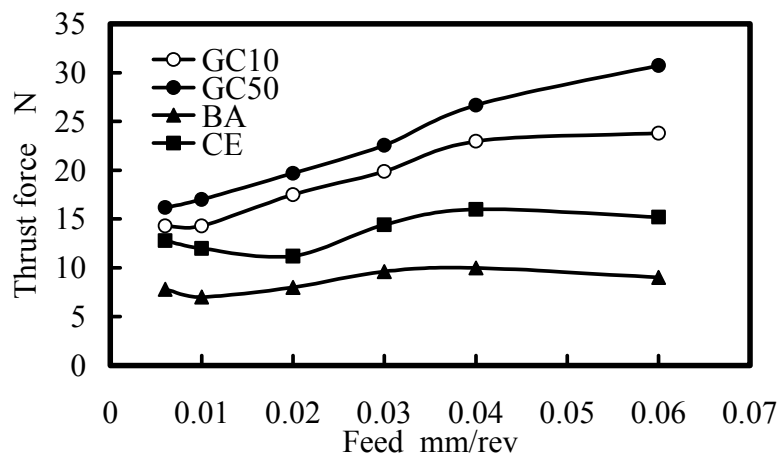

Figure 5: $\quad$ Progress of maximum thrust force when drilling workpieces. 
gradually by machining at the brad point, but increases significantly by the short auger bit in the next processing. However, the thrust force of CE is small, and shows gradual variations.

Figure 5 shows the relationship between the feed rate and the maximum thrust force under the cutting speed of $15 \mathrm{~m} / \mathrm{min}$ with the metal drill. The maximum thrust force of GC increases as the feed rate is increased, however, the other workpieces hardly increase. The maximum thrust force of the wood drill is about four times larger than that of the metal drill.

\subsection{Specific cutting force}

The cutting force per length named specific cutting force was calculated by

$$
k_{s}=\frac{F_{\max }}{f_{d}}
$$

where $k_{s}$ is the specific cutting force, $F_{\max }$ the maximum thrust force and $f_{d}$ the feed rate.

Figure 6 shows the specific cutting force when drilling GC50 using the metal drill. The cutting speed and the feed rate range from $10 \mathrm{~m} / \mathrm{min}$ to $25 \mathrm{~m} / \mathrm{min}$ and from $0.006 \mathrm{~mm} / \mathrm{rev}$ to $0.06 \mathrm{~mm} / \mathrm{rev}$, respectively. From this figure, the specific cutting force increases as the feed rate is decreased. The increasing tendency affected by the roundness of the cutting edge is known as effect of size. The specific cutting force is constant at the feed rate of $0.03 \mathrm{~mm} / \mathrm{rev}$ and above.

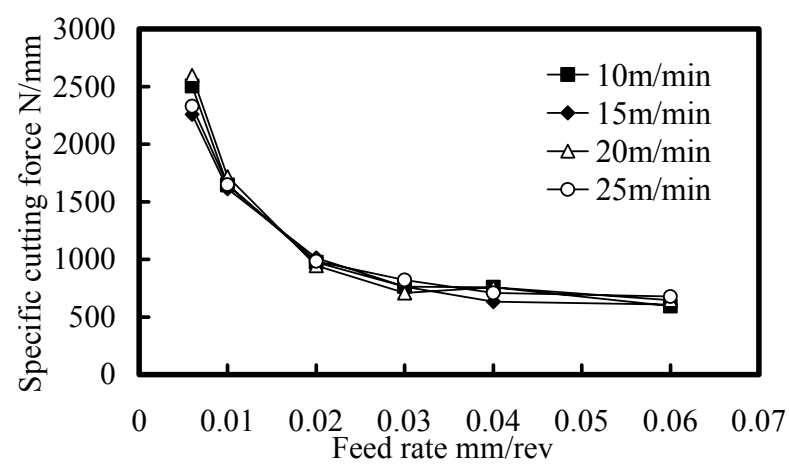

Figure 6: Variation of specific cutting force when drilling GC50 using the metal drill.

Figure 7 compares the specific cutting force of the metal drill and the wood drill at the cutting speed of $15 \mathrm{~m} / \mathrm{min}$. The specific cutting force of the wood drill is considerably larger than that of the metal drill. It is guessed that the tool geometry of the wood drill affected the specific cutting force. As shown in Fig.1, the wood drill has two kinds of the cutting edges. These edges are fed simultaneously toward the directions parallel (cutting edge A) and normal 
(cutting edge B) to the cutting surface. On the other hand, the metal drill has only the two cutting edges, which are fed parallel to the cutting surface. The edges of metal drill are symmetrically distributed at the drill axis. In the case of the wood drill, the cutting edge of normal direction shears the circumference of hole, and circularizes the profile of the drilled hole. However, the normal direction cannot shear the fiber.

Figure 8 shows the progressive curve of specific cutting force when drilling workpieces with the metal drill at the cutting speed of $15 \mathrm{~m} / \mathrm{min}$. The specific cutting force indicates a substantially constant value at the feed rate of $0.03 \mathrm{~mm} / \mathrm{rev}$ over. The specific cutting force becomes larger at a low feed rate range in all workpieces. The specific cutting force of $\mathrm{GC}$ is the largest. It is known that the specific cutting force is affected by the tensile strength of the workpiece. As mentioned above, it is clear that the specific cutting force of GC is large because the tensile strength of GC is bigger than that of CE.

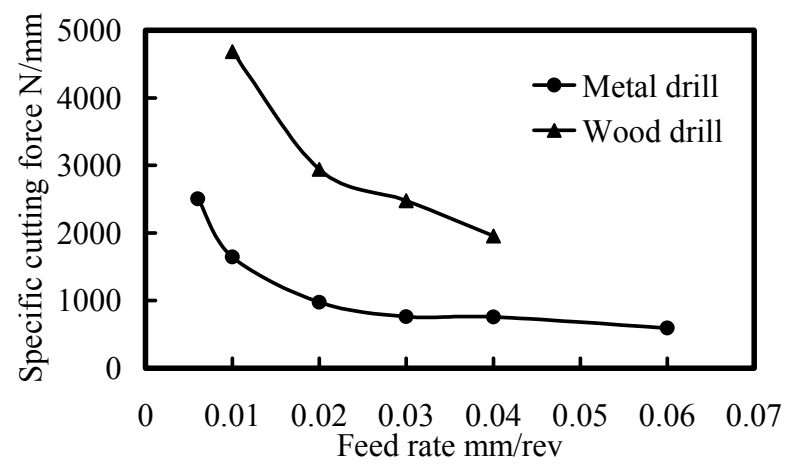

Figure 7: Comparison of specific cutting force between the metal drill and the wood drill.

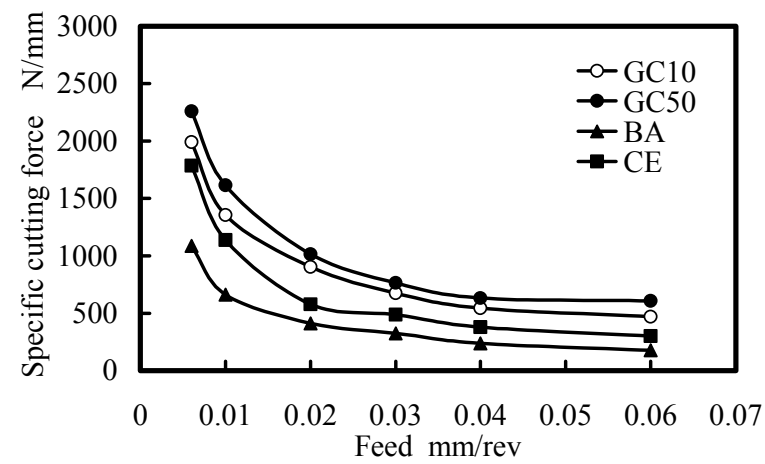

Figure 8: Comparison of specific cutting force among various workpieces. 


\subsection{Drilled hole}

Figure 9 shows the appearance of the drilled hole at the entrance and exit which was observed by a digital microscope when drilling $\mathrm{GC}$ at the cutting speed of $15 \mathrm{~m} / \mathrm{min}$ and the feed rate of $0.03 \mathrm{~mm} / \mathrm{rev}$ with the metal drill and the wood drill. In the case of the metal drill, the burr and the fuzz are observed at the entrance and exit on the workpiece surface. Compared with the entrance side, the exit side fuzzes. At the entrance surface, the fuzz happens in the run out of the drill and the ripping of the cutting edge. The burr of the exit surface occurred when the drill pierced there. As the drilling numbers increase, the burr size remained small. However, the burr size was large when the feed rate increases. At the exit, the fiber isn't cut sharply, so the burr is fuzzing in the rotational direction. The appearance of the drilled hole when using the wood drill is very rough. The drilled hole has the fuzz at the entrance, and the burr at the exit. The wood drill as well as the metal drill cannot cut the single fiber of GC. The burr is generated in parallel to the fiber direction, and the fuzz is ugly. Probably, compared with the fiber diameter, the corner radius of the drill is too big to shear the single fiber in drilling of GC.

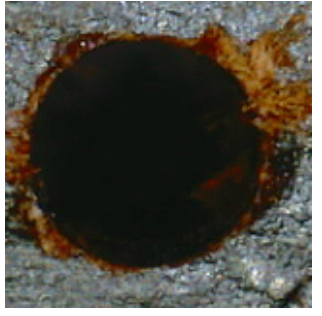

(i) Entrance

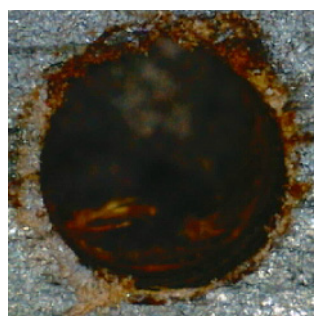

(i) Entrance

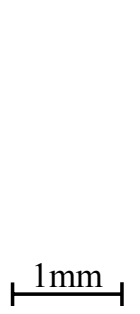

(a) Metal drill

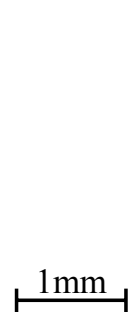

(b) Wood drill

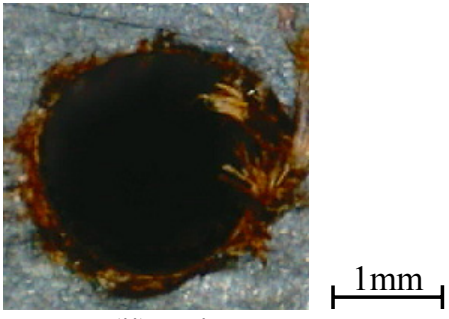

(ii) Exit

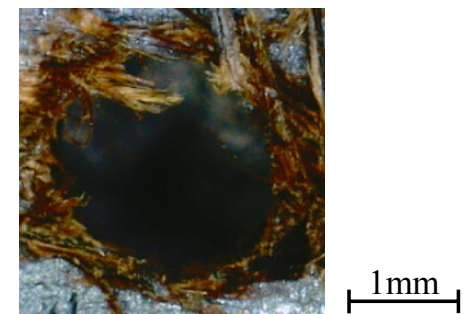

(ii) Exit

Figure 9: Appearance of the hole at the entrance and exit when drilling GC50. 


\subsection{Chip form}

Figure 10 shows the chip form of GC and CE at the cutting speed of $15 \mathrm{~m} / \mathrm{min}$ and the feed rate of $0.03 \mathrm{~mm} / \mathrm{rev}$. In the case of the metal drill, the chip form is long and thick, but doesn't fuzz. The chip form is a discontinuous type. The form of generated chip was easy to pulverize by an applied load. Compared with the chip length of GC10, that of GC50 is long. The bonding force of GC fiber is probably affected by higher forming pressure in its processing. The chip thickness of BA and CE was very thin. In the case of the wood drill, on the other hand, in all workpieces the chip thickness is very thick and the chip form fuzzes significantly.

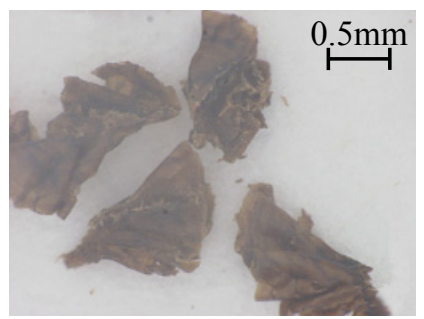

(i) $\mathrm{GC} 10$

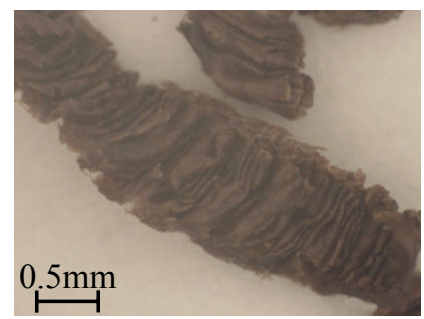

(ii) GC50

(a) Metal drill

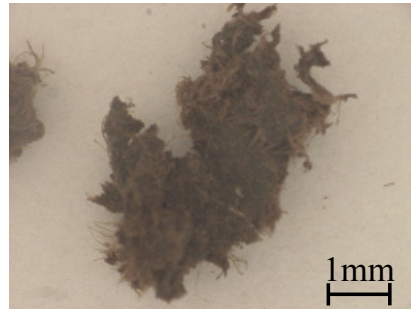

(i) $\mathrm{GC} 10$

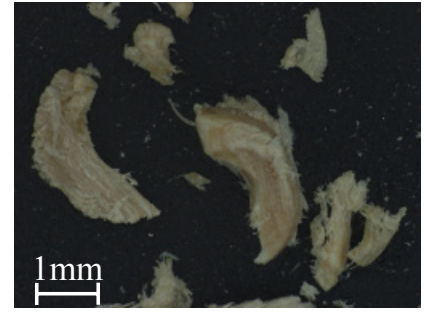

(ii) $\mathrm{CE}$

(b) Wood drill

Figure 10: Chip appearance for different tools.

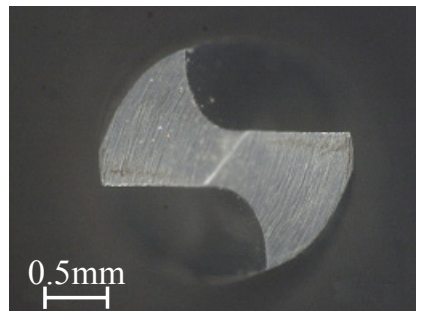

(a) GC10

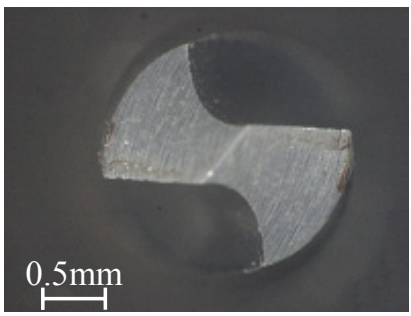

(b) GC50

Figure 11: Tool failure patterns of the metal drill after 100 drillings. 


\subsection{Tool wear of metal drill}

Figure 11 shows the tool wear after 100 drillings in GC at the drilling conditions of the cutting speed of $15 \mathrm{~m} / \mathrm{min}$ and the feed rate of $0.03 \mathrm{~mm} / \mathrm{rev}$ with the metal drill. There were too few drilling numbers to find the tool wear. The chisel edge acts as the cutting edge at a negative large rake angle, and the cutting speed at the edge becomes nearly zero, however the tool wear grows easily because of the thrust force generated by giving the feed rate to the drill. In order to reduce the abrasion of the chisel edge, the thinning which decreases the thrust force by removing part of this edge is effective.

\section{Discussion}

The machinability of resin-less bamboo composites was discussed by four factors: the tool wear, the thrust force, the chip form and the hole appearance. This paper deals with the machinability in drilling of GC, CE and BA using the metal drill and the wood drill. First of all, the tool wear was hardly observed because of the small number of drillings. Secondly, the thrust force showed the corresponding mechanical properties to each workpieces. Third, the chip form was the discontinuous type. Finally, the hole appearance was unsatisfactory in all drilling conditions. The disfigurements were observed at the entrance and exit. The cutting speed of $15 \mathrm{~m} / \mathrm{min}$ and the feed rate of $0.03 \mathrm{~mm} / \mathrm{rev}$ resulted in the smallest burr sizes in the drilling conditions. Furthermore, the appearance of the drilled hole was affected by not only the drilling conditions but also the tool geometries. The cutting edge of the drills has not been sharp because the fiber of $\mathrm{GC}$ fuzzed. In order to shear the single fiber of GC, it is considered preferable to use an electroplated diamond tool with a sharp cutting edge.

\section{Conclusions}

This paper compared and evaluated thrust force, chip form, hole appearance and tool wear to examine the machinability of resin-less "green" composites when drilling various workpieces with a metal drill and a wood drill. The conclusions obtained are as follows.

(1) The thrust force of GC in drilling is larger than that of CE and BA.

(2) Compared with the specific cutting force of $\mathrm{GC}$, that of $\mathrm{CE}$ and $\mathrm{BA}$ is small because of lower tensile strength.

(3) The chip length of GC is longer than that of $\mathrm{CE}$ and BA. The chip length increases with increasing forming pressure.

(4) The small disfigurements around the drilled holes in drilling of GC are observed at the cutting speed of $15 \mathrm{~m} / \mathrm{min}$ and the feed rate of $0.03 \mathrm{~mm} / \mathrm{rev}$ using the metal drill.

(5) The wood drill is inadequate to drill GC because of the large thrust force, the ugly hole appearance and the unshapely chip form compared to the metal drill. 


\section{Acknowledgement}

The authors are very grateful to Mr. Hiroshi Mori who supplied the specimen and related data for resin-less bamboo composites.

\section{References}

[1] Fujii, T. \& Okubo, K., Eco-composites using bamboo. Sen'i Gakkaishi, 59(3), pp. 84-88, 2003.

[2] Ohshima, K., The actual situation and problem of the biodegradable plastics. Journal of the Japanese Society of Revegetation Technology, 28(4), pp. 490 496, 2003.

[3] Hills, W. E. \& Rozsa, A. N., High temperature and chemical effects on wood stability. Wood Science and Technology, 19(1), pp. 57-66, 1985.

[4] Wollerdorfer, M. \& Bader, H., Influence of natural fibres on the mechanical properties of biodegradable polymers. Industrial Crops and Products, 8(2), pp. 105-112, 1998.

[5] Prasad, B. \& Sain, M., Mechanical properties of thermally treated hemp fibers in inert atmosphere for potential composite reinforcement. Materials Research Innovations, 7(4), pp. 231-238, 2003.

[6] Chabba, S. \& Netravali, A., 'Green' composites using modified soy protein concentrate resin and flax fabrics and yarns. JSME International Journal Series A, 47(4), pp. 556-560, 2004.

[7] Okubo, K., Takagi, H. \& Goda, K., Green composites' research and today's progress. Journal of the Society of Materials Science, 55(4), pp. 438-444, 2006.

[8] Gomes, A., Matsuo, T., Goda, K. \& Ohgi, J., Development and effect of alkali treatment on tensile properties of curaua fiber green composites. Composites Part A-Applied Science and Manufacturing, 38(8), pp. 18111820, 2007.

[9] Mori, H. \& Takagi, H., Development of new "green" composites without using artificial polymers. Proceedings of Mechanical Engineering Congress, pp. 531-532, 2005. 